\title{
Penerapan dan Analisis Virtualisasi Router Menggunakan RouterOS
}

\author{
Asmunin, Aditya Hermawan \\ Jurusan Teknik Informatika \\ Fakultas Teknik \\ Universitas Negeri Surabaya \\ asmunin@unesa.ac.id,Hermawan.aditya05@gmail.com
}

Diterima: 8 Maret 2016. Disetujui: 12 April 2016. Dipublikasikan: Mei 2016

\begin{abstract}
Abstrak - Dewasa ini, virtualisasi dan cloud computing telah menjadi tren teknologi informasi khususnya untuk perusahaan skala enterprise. MetaROUTER merupakan implementasi virtualisasi pada RouterOS v3.21 keatas yang berjalan pada RouterBoard dengan platform MIPS-BE. Fokus penelitian ini adalah virtualisasi router berbasis MetaROUTER dimana antar virtual router tidak saling berhubungan dan memiliki fungsi yang berbeda. Fungsi dari masingmasing virtual router adalah manajemen bandwith dengan PCQ, proxy server dan hotspot yang teintegrasi dengan PCQ. Skenario pengujian meliputi empat aspek yakni independensi, performa, throughput dan security. Hasil pengujian menunjukkan bahwa penggunaan memori untuk tiap skenario pengujian pada virtual router relatif sama yakni tersisa $5.1 \mathrm{MB}$ untuk download, 5.8MB untuk browsing, dan 5.3MB untuk hotspot. Untuk CPU load, aktivitas download membutuhkan CPU paling banyak, yakni 13\%. Untuk throughput, pada VR1 nilai TX berada pada nilai 1013Kbps sedangkan $R X$ pada nilai $30 \mathrm{Kbps}$, VR2 sebesar $122.435 \mathrm{~KB} /$ detik, dan VR3 sebesar 119.617KB/detik. Hasil pengujian security menunjukkan bahwa tiap virtual router tidak dapat mengirim paket ICMP ke router utama karena rule drop pada firewall.
\end{abstract}

Keywords: RouterOS;MetaROUTER; virtualisasi; cloud computing.

\section{PENDAHULUAN}

Virtualisasi artinya menciptakan versi virtual dari sistem operasi, sumber daya jaringan maupun perangkat penyimpanan [1]. Tujuan virtualisasi adalah efisiensi baik dari segi cost, resource, energy atau risk. RouterOS adalah sistem operasi berbasis kernel linux yang mengubah PC menjadi router. Fitur jaringan pada routerOS antara lain routing, firewall, Quality of Service, wireless network, authentication, IP Tunnel, interface dan service. RouterOS memiliki enam level lisensi, dimana semakin tinggi lisensi modulnya semakin lengkap dan harganya semakin mahal.
RouterBoard (RB) adalah hardware router yang dibuat oleh mikrotik dan telah terpasang RouterOS. Terdapat sistem pengkodean tertentu pada RouterBoard sehingga pengguna dapat mengetahui fiturnya, misalkan RB433 memiliki arti seri router (4), jumlah port ethernet (3), dan jumlah slot miniPCI (3). Kode lain yang sering digunakan antara lain U (dilengkapi USB), A (Advanced), H (High Performance), R (dilengkapi wireless Card), dan $G$ (terdapat port gigabit) [2]. RouterOS mendukung tiga (3) jenis virtualisasi yakni MetaROUTER, Xen, dan KVM (Kernel-based Virtual Machine) [1]. MetaROUTER adalah implementasi teknologi virtualisasi pada RouterOS v3.21 ke atas, berjalan pada RouterBoard dengan platform MIPS-BE seri RB400, dapat menjalankan mesin RouterOS dan OpenWRT virtual, RAM minimal 16MB (32MB lebih baik), dan hanya dapat menjalankan maksimal 8 mesin virtual setiap RouterBoard [1].

\section{METODE PENELITIAN}

Penelitian sebelumnya yang terkait dengan topik ini antara lain: arsitektur dan virtualisasi server dengan enkripsi virtual machine [3], keamanan teknik virtualisasi dan cloud computing[4], pengaruh virtualisasi pada keamanan informasi [5], perbandingan unjuk kerja virtualisasi [6], pentingnya virtualisasi pada cloud computing[7] dan survey penelitian terkait teknologi virtualisasi [8]. Fokus penelitian ini adalah virtualisasi router menggunakan routerOS, dimana antar virtual router dengan yang lain tidak saling berhubungan. Setiap virtual router dijadikan router untuk client sehingga seolah-olah memiliki router fisik. Skema jaringan yang digunakan terlihat pada Gambar 1. 


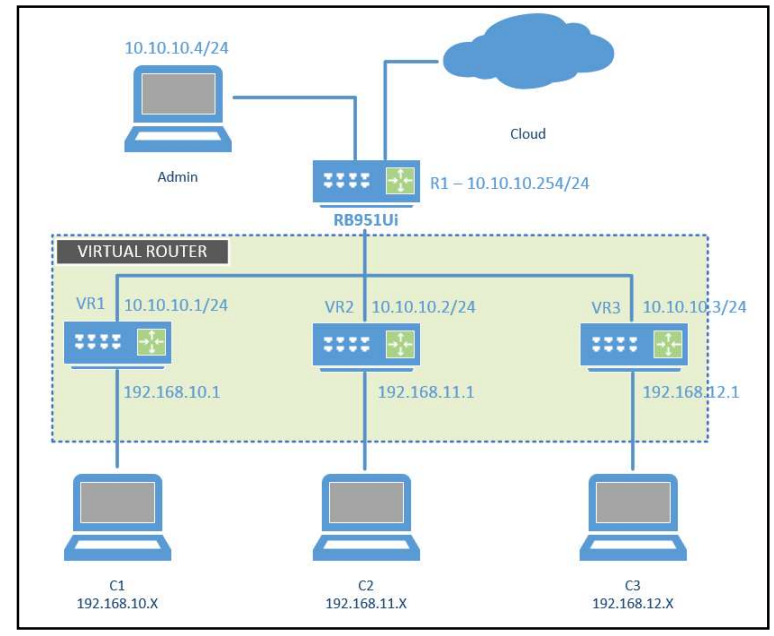

Gambar 1. Skema Jaringan Virtualisasi Router

Pada Gambar 1, R1 adalah router fisik RB RB951Ui yang berfungsi sebagai host dan merupakan router induk sedangkan VR1, VR2, dan VR3 adalah virtual router yang berfungsi sebagai guest. Router R1 terhubung langsung ke internet dan menyediakan layanan virtualisasi sedangkan virtual router (VR1, VR2, VR3) terhubung ke tiap-tiap client. $\mathrm{C} 1, \mathrm{C} 2$, dan $\mathrm{C} 3$ adalah client berupa $\mathrm{PC} /$ Laptop yang terhubung ke virtual router.

Fungsi dari masing-masing virtual router adalah: [9] - VR1 berfungsi sebagai manajemen bandwith dengan metode PCQ (Per Connection Queue) sehingga setiap client mendapat pembagian bandwith secara adil.

- VR2 berfungsi sebagai proxy server.

- VR3 berfungsi sebagai hotspot yang terintegrasi dengan PCQ.

Tahapan penelitian meliputi pembuatan skema jaringan, konfigurasi virtualisasi (host dan guest), dan pengujian. Skema jaringan meliputi arsitektur jaringan dan alamat IP (Internet Protocol) pada masing-masing node, seperti terlihat pada Gambar 2.[10] Terdapat empat skenario pengujian yang dilakukan pada tiap-tiap virtual router antara lain independensi, performa, throughput, dan security [11]. Detail masing-masing pengujian adalah sebagai berikut:

1. Independensi, untuk mengetahui bahwa antar virtual router satu dengan yang lain tidak saling bergantung [12].

2. Performa, untuk mengetahui unjuk kerja dari masing-masing virtual router.

3. Throughput, untuk melakukan pengukuran kecepatan transfer data yang sebenarnya pada tiap virtual router.

4. Security, untuk menguji apakah R1 dapat diakses langsung oleh client atau tidak. Pengujian dilakukan dengan tools yang tersedia pada mikrotik.

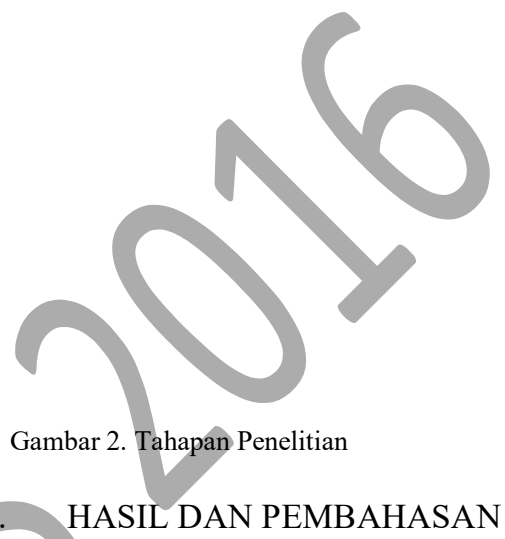

Perangkat keras yang digunakan pada penelitian ini antara lain: R1 adalah RouterBoard seri RB951Ui dengan spesifikasi CPU AR9344 $600 \mathrm{MHz}$, RAM $128 \mathrm{MB}$, NAND $128 \mathrm{MB}$, LAN port 5 , routerOS level 4. Sedangkan untuk PC client, Processor Intel Dual Core 1037 (1.8 Ghz), RAM 2 MB, Harddisk 500GB. Pengujian independensi bertujuan untuk mengetahui kinerja virtual router sesuai fungsinya. Hasil uji coba independensi adalah sebagai berikut:

1. VR1, dengan pengaturan bandwithupload $512 \mathrm{~kb}$, dan download $1 \mathrm{Mb}$ pada Queue Tree List. Hasil uji coba menunjukkan bandwith maksimal yang diperoleh setiap client adalah sesuai konfigurasi bandwith maksimal yang diberikan, terlihat pada Gambar 3.

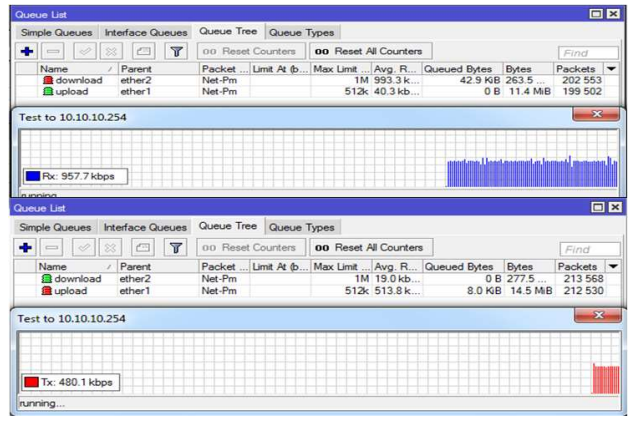

Gambar 3. Uji Coba Queue Tree Download dan Upload Vr1

2. VR2, pengujian dilakukan pada manajemen HIT dan MISScache proxy. Hasil uji coba menunjukkan internet proxy berfungsi dengan baik. Konten web yang telah dikunjungi tersimpan pada cache sehingga jika terdapat 
pengguna lain mengakses konten yang sama, maka konten dalam cache langsung diberikan tanpa mengunjungi website sehingga menjadi cepat.

3. VR3 (Virtual Router 3), pengujian dilakukan pada fungsi dari hotspot dan manajemen bandwith berbasis PCQ. Hasil pengujian menunjukkan bahwa ketika memori VR3 dialokasikan 24MB, halaman login hotspot tidak dapat muncul. Sedangkan ketika memori pada VR3 diubah menjadi 32MB, maka halaman login hotspot pada VR3 dapat berfungsi dengan baik. Hotspot tidak berfungsi pada memori $24 \mathrm{MB}$ disebabkan karena rule firewall pada hotspot tidak mendapatkan resource yang cukup.

Pengujian performa bertujuan untuk mengetahui penggunaan resource dari tiap virtual router. Skenario dan hasil uji coba performa sebagai berikut:

1. VR1, skenario ujicoba dengan satu client melakukan download file dari internet, dan dilakukan monitoring resource. Hasil pengujian adalah CPU load mencapai 13\%, total memori yang dialokasikan 24MB tersisa 5.1 MB, free HDD space $99.3 \mathrm{MB}$.

2. VR2, skenario ujicoba dengan satu client melakukan browsing dan dilakukan monitoring resource yang digunakan. Hasil ujicoba adalah CPU load 9\%, sisa memori 5.8MB dari 24MB.

3. VR3, pengujian dilakukan dengan satu client melakukan login pada hotspot dan dilakukan monitoring resource. Hasil uji coba, CPU load $4 \%$, sisa memori menjadi $5.3 \mathrm{MB}$ dari $24 \mathrm{MB}$. Ketika alokasi memori ditambah menjadi $32 \mathrm{MB}$ memori menjadi $14.9 \mathrm{MB}$ seperti terlihat pada Gambar 4.

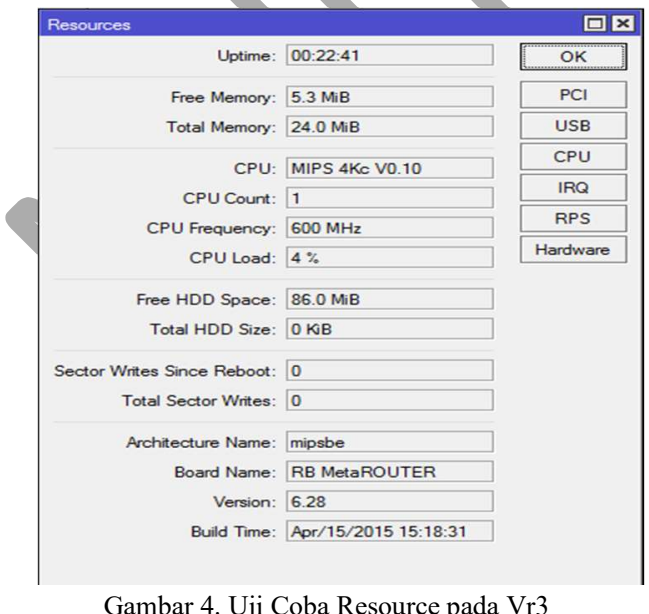

Hasil pengujian performa menunjukkan bahwa penggunaan memori untuk tiap skenario pengujian pada virtual router relatif sama yakni tersisa 5.1MB untuk download, 5.8MB untuk browsing, dan 5.3MB untuk hotspot. Untuk CPU load, aktivitas download membutuhkan CPU paling banyak, yakni 13\%.

Pengujian throughput bertujuan untuk mengetahui kecepatan transfer data riil pada tiap virtual router. Pengujian dilakukan dengan melakukan download menggunakan IDM (Internet Download Manager). Hasil pengujian pada VR1 terlihat pada Gambar 5.

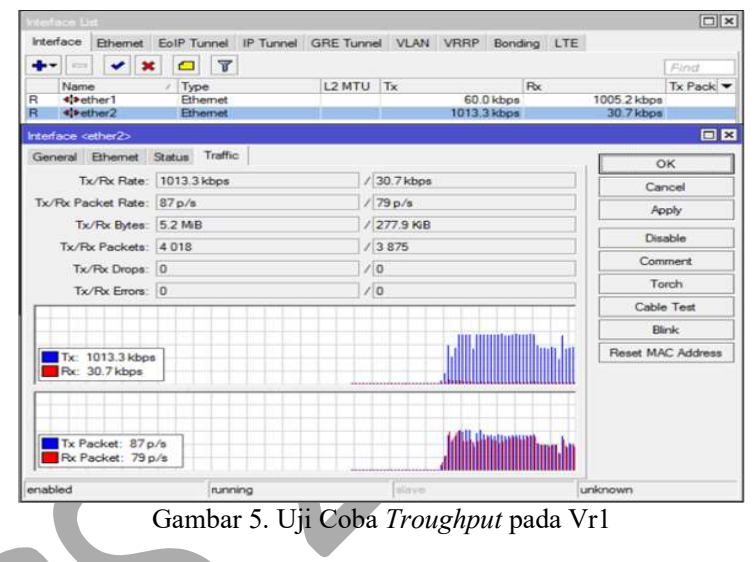

Berdasarkan Gambar 5 terlihat bahwa pada grafik TX(transmit) berada pada nilai $1013 \mathrm{Kbps}$ sedangaan $\mathrm{RX}$ (receiver) berada pada nilai $30 \mathrm{Kbps}$, hal ini merupakan total bandwith keseluruhan yang diberikan kepada metarouter. Sedangkan kecepatan riil pada IDM menghasilkan throughput sebesar 119.073 KB/detik, terlihat pada Gambar 6.

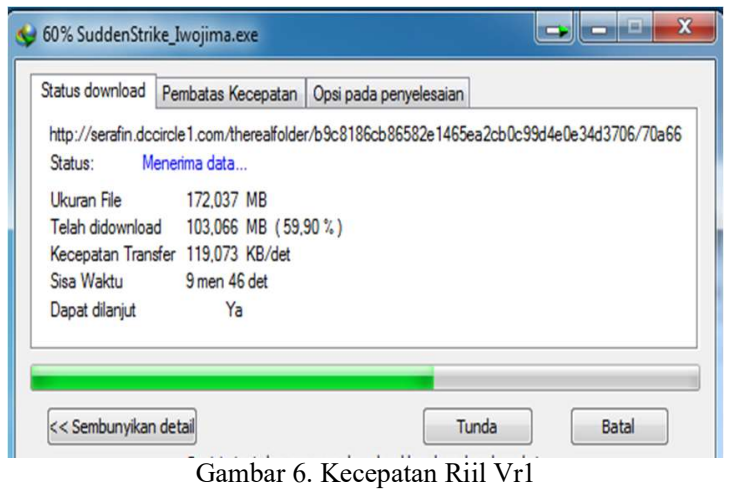

Pengujian throughput pada VR2 yang difungsikan sebagai proxy dilakukan sebelum dan sesudah tersimpan dalam cache. Hasil throughput yang dihasilkan sebelum data tersimpan dalam cache proxy adalah $122.435 \mathrm{~KB} /$ detik. Hasil pengujian pada data setelah tersimpan pada cache proxy tidak dapat dilakukan karena resource memori tidak cukup.Hasil throughput pada VR3 sebesar 119.617KB/detik. Hasil pengujian ini dilakukan setelah melalui beberapa proses manajemen bandwith dengan PCQ sehingga bandwith terbagi merata pada tiap client seperti pada Gambar 7. 


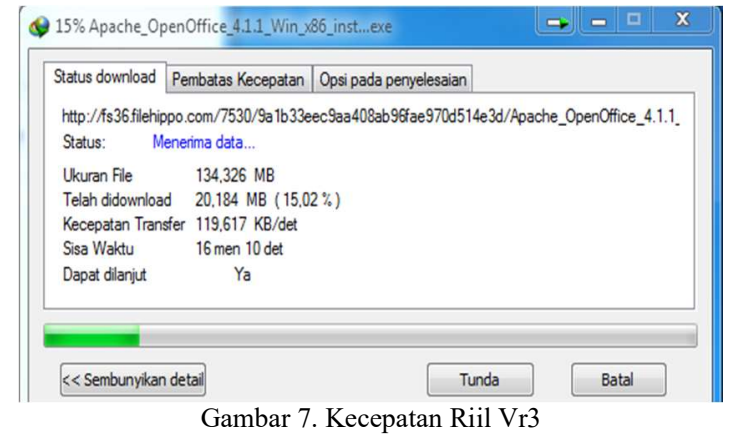

Pengujian security bertujuan untuk mengetahui keamanan pada router utama (RB951Ui), apakah masih bisa diakses oleh client. Pengujian dilakukan dengan mengirim paket ICMP (Internet Control Message Protocol) dari tiap virtual router. Hasil pengujian security pada Gambar 8 menunjukkan bahwa tiap virtual router tidak dapat mengirim paket ICMP ke router utama karena rule drop pada firewall.

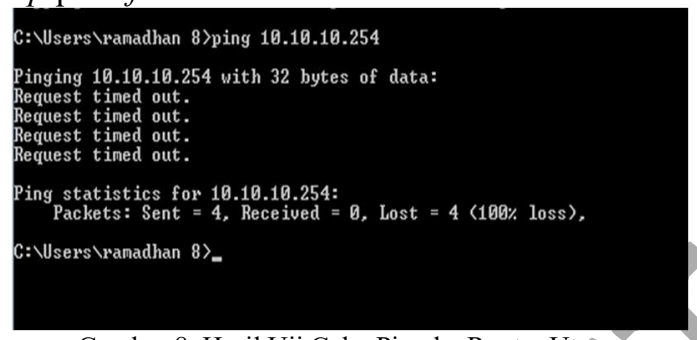

Gambar 8. Hasil Uji Coba Ping ke Router Utama

Selain ping, pengujian security juga dilakukan dengan melakukan telnet, ssh dan webconfig. Pengujian ini bertujuan untuk memastikan router utama hanya dapat diakses oleh komputer admin dengan IP 10.10.10.14, untuk keperluan konfigurasi dan perawatan. Hasil pengujian menunjukkan bahwa semua virtual router tidak dapat mengakses router utama, karena rule drop pada firewall dan hanya dapat diakses dari komputer admin dengan IP 10.10.10.14, terlihat pada Gambar 9 .

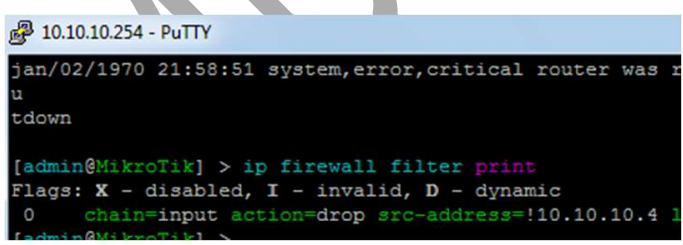

Gambar 9. Hasil Uji Coba SSH

\section{KESIMPULAN}

Hasil pengujian menunjukkan bahwa penggunaan memori untuk tiap skenario pengujian pada virtual router relatif sama yakni tersisa 5.1MB untuk download, 5.8MB untuk browsing, dan 5.3MB untuk hotspot. Untuk CPU load, aktivitas download membutuhkan CPU paling banyak, yakni 13\%. Untuk throughput, pada VR1 nilai TX(transmit) berada pada nilai $1013 \mathrm{Kbps}$. Sedangkan RX(receiver) berada pada nilai $30 \mathrm{Kbps}$, VR2 sebesar $122.435 \mathrm{~KB}$ /detik, dan VR3 sebesar 119.617KB/detik. Hasil pengujian security menunjukkan bahwa tiap virtual router tidak dapat mengirim paket ICMP ke router utama karena rule drop pada firewall.

\section{REFERENSI}

[1] R. T and Herman, Mikrotik MetaRouter 100\% iLLusion, Jakarta: Jasakom, 2016.

[2] R. Towidjojo, Konsep dan Implementasi Routing dengan Router Mikrotik, Jakarta: Jasakom, 2012

[3] D. Sarddar and R. Bose, "Architecture of Server Virtualization Technique Based on VMware ESXI server in the Private Cloud for an Organization," International Journal of Innovation and Scientific Research, pp. 284-294, 2014.

[4] F. Lombardi and R. Di Pietro, "Secure virtualization for cloud computing," Journal of Network and Computer Applications, 2010.

[5] S. Han Li, D. C.Yen and S. Chih Chen, "Effects of virtualization on information security," Computer Standards \& Interfaces, pp. 1-8, 2015.

[6] R. Rasian and P. Mursanto, "PERBANDINGAN KINERJA PENDEKATAN VIRTUALISASI," Jurnal Sistem Informasi Vol.5 No 2, pp. 90-99, 2009.

[7] R. Kumar and S. Charu, "An Importance of Using Virtualization Technology in Cloud Computing," Global Journal of Computers \& Technology, pp. 56-60, 2015.

[8] F. R. Haro, F. Freitag and L. Navarro, "A summary of virtualization techniques," Procedia Technology 3, pp. 267272,2012

[9] K. T. Koganti, E. Patnala, S. S. Narasingu and J. Chaitanya, "Virtualization Technology in Cloud Computing Environment," International Journal of Emerging Technology and Advanced Engineering, pp. 771-773, 2013.

[10] T. I. Bayu, I. R. Widiasari and D. W. Chandra, "Penerapan Teknologi Virtualisasi Tingkat Sistem Operasi pada Server Linux Ubuntu 8.04 menggunakan OpenVZ," Jurnal Teknologi Informasi-Aiti, pp. 68-85, 2010.

[11] K. T. Koganti, E. Patnala, S. S. Narasingu and J. Chaitanya, "Virtualization Technology in Cloud Computing Environment," International Journal of Emerging Technology and Advanced Engineering, pp. 771-773, 2013.

[12] Y. Wang, P. Chau and F. Chen, "Towards a secured network virtualization," Computer Networks, pp. 55-65, 2016 